\title{
A tradução intersemiótica no filme $O$ buraco
}

\author{
Janailton Mick Vitor da Silva ${ }^{2}$ \\ Sinara de Oliveira Branco ${ }^{3}$
}

\begin{abstract}
Resumo: O objetivo deste artigo é descrever o uso da tradução intersemiótica no filme $O$ Buraco (2009), analisar as implicações dessa categoria tradutória e seu resultado em tal contexto, a partir da compilação, quantificação e estudo de cenas com e sem legendas, e justificar a relevância da interpretação de imagens em cenas sem legendas. Enfatizamos aqui a interdisciplinaridade entre Estudos da Tradução e áreas como Linguística, Legendagem, Cinema e Estudos Intersemióticos. Seguimos o paradigma interpretativista, a metodologia descritiva e a tipologia quanti-qualitativa, selecionamos 43 cenas, 11 (26\%) sem legendas e 32 (74\%) com legendas. Nas 06 (seis) cenas selecionadas para análise, que retratam os traumas de infância dos personagens e a sua dissolução, os resultados apontam que a tradução intersemiótica supriu perdas de sentido, pois imagens e legendas se complementam. Nas cenas sem legendas, a imagem predominou pela falta de diálogos e pelo auxílio de elementos que contribuíram para a compreensão (cenários, gestos, sons etc.). Porém, quando foi necessário prover informações específicas sobre o conflito e dissolução do trauma de cada personagem, o código verbal, em consonância com a imagem e elementos intersemióticos, ganhou relevância.
\end{abstract}

Palavras-chave: Tradução intersemiótica. Legendagem. Cinema.

\section{The intersemiotic translation in the film The hole}

\begin{abstract}
This paper aims to describe the use of the intersemiotic translation in The Hole (2009), analyze its implications and results through the compilation, quantification and the study of scenes with and without official subtitles, and justify the relevance of the interpretation of images in the scenes without subtitles. The paper highlights the interdisciplinary work of Translation Studies with such areas as Linguistics, Subtitling and Cinema. Based on the interpretative paradigm, the descriptive methodology, the quanti-qualitative research typology,

43 scenes have been selected, among of which 11 (26\%) scenes do not have subtitles and 32 (74\%) scenes have subtitles. Findings from the 06 analyzed scenes, which depicted character's traumas and healings, have shown that the intersemiotic translation has prevented the lack of comprehension, because of the fact that images and subtitles have complemented each other. In the scenes without subtitles, images got relevance due to the absence of dialogues and the support of elements which contributed to the comprehension of the scenes (scenarios, gestures, sounds etc). However, subtitles, along with the image and intersemiotic elements in the scenes, were necessary when specific information needed to be provided regarding characters' traumas and their healings.
\end{abstract}

\footnotetext{
${ }^{1} \mathrm{O}$ presente trabalho foi realizado com o apoio do Conselho Nacional de Desenvolvimento Científico e Tecnológico - CNPq - Brasil.

${ }^{2}$ Estudante do Curso de Letras/Língua Inglesa na Universidade Federal de Campina Grande (UFCG). Aplicador dos testes de TOEFL ITP Assessment Series na UFCG. Bolsista de Iniciação Científica (PIBIC/CNPq/UFCG, atuando na linha de pesquisa Tradução Intersemiótica e Cinema (2013-2014).

${ }^{3}$ Doutora e Mestre Tradução pela Universidade Federal de Santa Catarin. Professora do curso de LetrasLíngua Inglesa, da Unidade Acadêmica de Letras, da Universidade Federal de Campina Grande. Atua também na Pós-Graduação em Linguagem e Ensino da mesma universidade. e-mail: sinarabranco@gmail.com
} 
Keywords: Intersemiotic translation. Subtitling. Cinema.

\section{Considerações iniciais}

Este artigo foi desenvolvido com base no projeto de pesquisa, Legendar ou não? Os gaps e seus sentidos no filme O Buraco, através do Programa Institucional de Bolsas de Iniciação Científica (PIBIC), ciclo 2013-2014.

A pesquisa entrelaçou os Estudos da Tradução com Cinema, Legendagem, Estudos Intersemióticos e Linguística. Buscou-se o trabalho com a Tradução Intersemiótica como uma das formas de compreensão de filmes no cinema, entendendo essa categoria tradutória como a tradução de signos linguísticos para não linguísticos e vice-versa (JAKOBSON, 2000; OUSTINOFF, 2011; PLAZA, 1987) em um filme norteamericano, O Buraco. como uma das formas de compreensão da trama.

Levando em conta que tanto imagens quanto legendas no cinema desempenham um papel importante para a narrativa e compreensão de histórias não causando falha na comunicação, o objetivo aqui é descrever o uso da Tradução Intersemiótica em $O$ Buraco (2009), buscando analisar as implicações de tal técnica tradutória e seu resultado em tal contexto. Para atingir este objetivo, foram necessárias:

i) a compilação e a quantificação das cenas com e sem legendas ${ }^{4}$ no filme; ii) a descrição, em gráficos e tabelas, da quantificação de cenas com e sem legendas; e, iii) a explicação da predominância da linguagem não verbal nas cenas sem legendas, caracterizando as imagens a partir de seu estudo.

O corpus deste estudo é a obra cinematográfica $O$ Buraco, de Joe Dante, que conta a história de dois adolescentes e uma criança: os irmãos Dane e Lucas. Depois de se mudarem para um novo bairro com a mãe, Susan, os irmãos conhecem a vizinha, Julie.

\footnotetext{
${ }^{4}$ As legendas analisadas foram as oficiais, ou seja, presents no DVD do filme.
} 
Juntos, os três descobrem um buraco lacrado no sótão da casa. Curiosos, eles não imaginam que, ao abrirem o buraco, além de não ter fundo, ele serve como um portal para que cada um deles enfrente seus medos. Com estranhas sombras à espreita e pesadelos ganhando vida, eles são forçados a encarar seus traumas mais profundos: Lucas (palhaços); Julie (o fantasma da sua melhor amiga de infância); Dane (o pai bêbado que lhe batia).

\section{Diálogos intersemióticos entre tradução, cinema e legendagem}

Para interagirmos e comunicarmos com o mundo ao redor, lançamos mão da leitura e da produção de diversas formas. Comunicamos também “[...] através de imagens, gráficos, sinais, setas, números, luzes... Através de objetos, sons musicais, gestos, expressões, cheiro e tato, através do olhar, do sentir e do apalpar” (SANTAELLA, 2005, p. 10).

Tendo em vista estas múltiplas linguagens, Oustinoff (2011) reitera a necessidade de se entender que a tradução abrange o campo oral e escrito, verbal e não verbal. Reforçando a existência de categorias de tradução, o autor expõe as três espécies de tradução desenvolvidas por Jakobson (2000, p. 114): i) a "tradução intralingual", que é a interpretação de signos verbais por outros signos da mesma língua; ii) a "tradução interlingual", que acontece a partir da tradução de signos verbais de uma língua por significados verbais de outra língua; iii) e a "tradução intersemiótica", que é a interpretação de signos linguísticos para não linguísticos e vice-versa.

Plaza (1987) defende que a tradução se faz presente nas formas mais diversas. Por exemplo, se pensamos sobre um determinado tema, a ideia desse tema irá constituirse em nossa mente pelo trabalho dos signos. Nesse sentido, "por seu caráter de transmutação de signo em signo, qualquer pensamento é necessariamente tradução.” (PLAZA, op. cit., p. 18). O autor busca ressaltar que, ao observar situações ou interpretar (con)textos, estamos traduzindo ideias para diferentes formas de linguagens, pois a expressão do pensamento humano é limitada pela linguagem. Para dar sentido ao mundo, a relação do homem com o universo ao redor é permeada pelos signos. Nesta perspectiva, "ao povoar o mundo de 
signos, dá-se um sentido ao mundo, o homem educa o mundo e é educado por ele, o homem pensa com os signos e é pensado pelos signos, a natureza se faz paisagem e o mundo uma 'floresta de símbolos'.” (PLAZA, op. cit., p. 19).

Esse pano de fundo reforça a importância de trabalhar a tradução intersemiótica como uma forma de compreender a transmutação de um signo linguístico para outro não linguístico. Considerando que um signo depende de outro para poder significar, isto é, a compreensão sobre um evento apenas se dá por outra compreensão mediada por uma tradução intersemiótica, os signos em foco “[...] têm tendência a formar novos objetos imediatos, novos sentidos e novas estruturas que, pela sua própria característica diferencial, tendem a se desvincular do original.” (PLAZA, op. cit., p. 30). Em outras palavras, quando há a tradução intersemiótica de um texto verbal para uma imagem, os signos verbais constituintes do primeiro veículo passam a formar novos signos não verbais que se complementam quando do surgimento do produto final. Por exemplo, pode-se observar como um excerto de um livro, descrevendo detalhadamente a constituição física de uma rosa, pode ser traduzido para uma imagem, trazendo para esse novo veículo não verbal detalhes minuciosos presentes no original, como traços dos espinhos, sombreamento, cores das pétalas e outros elementos presentes no texto de partida. Nesse contexto, o oposto também pode ocorrer.

A relação da tradução com a intermídia e multimídia é outro aspecto pontuado por Plaza (op. cit.). Nota-se uma relação de categorias voltadas ao meio tecnológico que produzem resultados abrangentes. Assim, elas levam a questionamentos sobre a existência de seus produtores, se há um único autor ou não, por exemplo. Além disso, Plaza (op. cit., p. 66) pondera que os meios tecnológicos envolvem diferentes sistemas sígnicos que traduzem distintas "[...] linguagens históricas para o novo suporte." Essas linguagens, de caráter transcodificado, acabam efetivando "[...] a colaboração entre os diversos sentidos, possibilitando o trânsito intersemiótico e criativo entre o visual, o verbal, o acústico e o tátil.” (PLAZA, 1987, p. 66).

O cinema é uma indústria cultural que lança no mercado filmes de diversos gêneros que trazem consigo características que podem ser estudadas sob o escopo da Tradução Intersemiótica, a partir da investigação entre imagens, legendas, sons etc., por exemplo. 
Bernardet (2006) pontua que os irmãos Lumière foram os inventores do cinema a partir da criação do cinematógrafo, aparelho que possui "[...] uma câmera que fotografa e projeta as imagens em uma velocidade de 16 quadros por segundo."

(SANTORO, 2007). Por meio da fotografia, o invento produz cenas animadas (PRIBERAM, 2015). Em 28 de dezembro de 1895, houve a exibição de filmes curtos gravados com a câmera parada, em preto e branco e sem som. Um deles emocionou o público ao mostrar uma locomotiva chegando à estação. Muito embora os telespectadores soubessem que não havia trem na tela, a ilusão criada pela imagem os marcou intensamente. "Essa ilusão de verdade, que se chama impressão de realidade, foi provavelmente a base do grande sucesso do cinema" (BERNARDET, op. cit., p. 12).

No cinema, o som se industrializou em 1928 e a imagem colorida chegou em 1950. Em termos de música, Bernardet (op. cit., p. 47) assume que “[...] a música acompanha o filme para, em geral, reforçar as emoções: exasperação na iminência do perigo, ternura em cenas românticas [...].” O autor complementa esse fato argumentando que, quando “[...] ouvimos a música, ela age sobre nós, mas não damos conta: a música também se torna transparente." (BERNARDET, 2006, p. 48).

O autor supracitado reforça a ideia de que não se pode acreditar que o cinema reproduz o movimento da vida.

[...] não há movimento na imagem cinematográfica. O movimento cinematográfico é uma ilusão, é um brinquedo ótico. A imagem que vemos na tela é sempre imóvel. A impressão de movimento nasce do seguinte: 'fotografa-se' uma figura em movimento com intervalos de tempo mais curtos entre cada 'fotografia' (= fotogramas). São vinte e quatro fotogramas por segundo que, depois, são projetados neste mesmo ritmo. (BERNARDET, 2006, p. 18).

Desse modo, o cinema não reproduz a vida, pois não há sequer movimento na imagem cinematográfica. O que acontece, de fato, é a passagem de 24 fotogramas em apenas um segundo, criando a ilusão de que o que se vê na tela está em movimento, quando, na verdade, é apenas a sequência ininterrupta de fotogramas. Assim, os filmes apresentam 
milhares de fotogramas projetados durante toda a sua duração. A montagem ocorre quando as imagens são colocadas uma após a outra.

$\mathrm{O}$ autor mencionado argumenta que o modo como as imagens são filmadas e estruturadas na tela é chamado de plano. Há sete tipos de planos, como observado no Quadro 01 a seguir.

Qua. 01 - Planos elencados por Bernardet (2006, p. 38).

\begin{tabular}{|c|c|}
\hline PLANOS & DEFINIÇÕES \\
\hline \multirow[t]{2}{*}{ Plano Geral (PG) } & $\begin{array}{l}\text { "[...] mostra um grande espaço no qual os } \\
\text { personagens não podem ser identificados }\end{array}$ \\
\hline & {$[\ldots] "$} \\
\hline \multirow{2}{*}{\multicolumn{2}{|c|}{$\begin{array}{r}\text { Plano de Conjunto (PC) "[...] mostra um grupo de } \mathrm{p} \\
\text { reconhecíveis, num ambiente }[\ldots] "\end{array}$}} \\
\hline & \\
\hline Plano Médio (PM) & $\begin{array}{l}\text { "[...] enquadra os personagens em pé com } \\
\text { uma pequena faixa de espaço acima da } \\
\text { cabeça e embaixo dos pés }[. . .] "\end{array}$ \\
\hline Plano Americano (PA) & $\begin{array}{l}\text { "[...] corta os personagens na altura da } \\
\text { cintura ou da coxa }[\ldots] "\end{array}$ \\
\hline Primeiro Plano (PP) & "[...] corta no busto $[\ldots] "$ \\
\hline Primeiríssimo Plano (PPP) & "[...] mostra só o rosto $[\ldots] "$ \\
\hline Plano de Detalhe & $\begin{array}{l}\text { "[...] mostra uma parte do corpo que não a } \\
\text { cara ou um objeto." }\end{array}$ \\
\hline
\end{tabular}

SILVA, J. M. V. Legendar ou não? Os gaps e seus sentidos no filme $O$ Buraco. Campina Grande: PIBIC/CNPq, 2014.

As cenas de filmes são caracterizadas pela junção de diversos planos que se entrelaçam ininterruptamente, exibindo, para o espectador, informações que são registradas pelas câmeras, podendo ir de uma perspectiva panorâmica (plano geral) a uma mais detalhada (plano de detalhe). Neste artigo, será observada se a constante mudança de planos pode auxiliar na compreensão das cenas quando na ausência de legendas oficiais.

Filmes podem apresentar legendas que traduzem a fala dos personagens do modo oral para o escrito, seja na mesma língua ou de uma língua para outra. A legendagem toma forma em textos audiovisuais, que são caracterizados pela conexão de dois tipos de canais, o acústico e o visual. Os elementos não verbais que se encontram nesses textos os tornam diferentes de outros tipos de texto (SOKOLI, 2009). Procedentes de monólogos ou diálogos produzidos por indivíduos e personagens em filmes ou vídeos em geral, as legendas são 
denominadas traduções escritas e condensadas, aparecendo como linhas de texto, comumente na parte inferior da tela (LUYKEN et al.,1991).

Georgakopoulou (2009) aponta que a confecção de legendas segue, a princípio, uma adequação ao espaço, tempo e apresentação. Díaz Cintas e Remael (2007) enfatizam que, como a legibilidade da legenda é de vital importância, a regra é que haja duas linhas de texto. Além disso, o comprimento da legenda está relacionado à sua duração de tempo na tela, não podendo ocupar mais do que $20 \%$ do espaço, obedecendo a fatores para sua melhor legibilidade, tais como tamanho dos caracteres, posição na tela e tecnologia utilizada para sua projeção no cinema (GEORGAKOPOULOU, 2009).

Em determinadas situações, as legendas podem ser omitidas por algumas restrições, como o espaço na tela. Porém, os espectadores ainda conseguem compreender determinada parte do vídeo ao perceber o contexto no qual as ações ocorrem, uma vez que há uma relação entre o que os indivíduos falam com a sequência de imagens. Desse modo, Georgakopoulou (op. cit., p. 25, tradução nossa) complementa que "a informação visual frequentemente ajuda os espectadores a processarem as legendas, e até certo ponto isto compensa a quantidade limitada de conteúdo verbal que elas contêm."5

Para o autor citado, há certos elementos que devem ser mantidos, condensados e dispensados nas legendas. Por exemplo, elementos enfatizando significados importantes sobre a trama precisam permanecer. Contudo, repetições, construções não gramaticais, palavras internacionalizadas ("Yes", “no", “ok"), expressões seguidas por gestos, exclamações (“oh”, “ah”, “wow”) etc. podem ser omitidas. Porém, pode haver situações nas

\footnotetext{
${ }^{5}$ The visual information often helps viewers process the subtitles, and to a certain extent this compensates for the limited verbal information they contain. (GEORGAKOPOULOU, 2009, p. 26-27).
} 
quais repetições e construções agramaticais deverão ser condensadas ao invés de eliminadas. (GEORGAKOPOULOU, op. cit., p. 26-27).

\section{Sistematizando o estudo de 'O Buraco'}

Segundo Moreira e Caleffe (2008, p. 62), o pesquisador que adota o paradigma interpretativista - nosso caso - “[...] é capaz de interpretar e articular experiências em relação ao mundo para si próprio e para os outros. Ele não está à parte da sociedade como um observador, mas constrói ativamente o mundo em que vive."

Os Estudos da Tradução seguem modelo descritivista e, portanto, observamos, cenas da obra cinematográfica, $O$ Buraco, investigando como a tradução intersemiótica trabalha para a compreensão e interpretação do filme pela audiência.

Baseando-se nessas informações, o primeiro passo desta investigação foi compilar as cenas do filme a serem analisadas. Ao selecionar estas imagens em movimento, fizemos a classificação entre as cenas legendadas e não legendadas e quantificamos as cenas. Em seguida, construímos o Gráfico 01 que exibe os resultados quantitativos da análise.

Após essa etapa, comparamos os aspectos linguísticos e visuais para justificar a omissão ou o uso de legendas oficiais no filme. Ao focalizar o uso de imagens não legendadas, por não apresentarem monólogos nem diálogos, investigaremos até que ponto as imagens são capazes de funcionar como interpretação da narrativa e se há perda de sentido pela ausência de legendas.

O último passo, a ser descrito mais adiante, será analisar a implicação e a relevância do uso da Tradução Intersemiótica em contexto fílmico.

\subsection{Compilação das cenas}

A compilação das cenas legendadas e não legendadas foi feita tomando como critério a presença de aspectos intersemióticos, tais como expressões emotivas (raiva, 
alegria, euforia, dor, medo, tristeza, humor, rancor, angústia etc.) e outros elementos (expressões faciais e corporais, efeitos sonoros, cenários etc.) que demonstram e contribuem para o desenrolar da trama e o clímax. Esse procedimento foi feito com o auxílio do programa Fraps ${ }^{6}$, que seleciona, de filmes, jogos e vídeos, alguns benchmarks (quantificação de sequência de imagens em movimento, por segundo), trechos de imagem em movimento (segmentos menores de vídeos) e captura da tela em até quatro formatos de imagem (BMP, JPG, PNG, TGA).

A versão utilizada (3.5.99) foi obtida gratuitamente na internet através de download. Após a instalação no computador, foram observadas algumas restrições para uso efetivo do programa, como a presença da marca d'água "www.fraps.com" nos pequenos trechos de vídeo do filme em estudo. Vale ressaltar que os vídeos são selecionados em trechos de até 29 segundos em um único arquivo no computador. Caso seja necessário selecionar mais do que esse tempo, um novo arquivo é criado automaticamente pelo programa a cada segundo que ultrapasse os 29 iniciais. A captura de benchmarks é feita pelo botão F11; de vídeos, através do F9; e de imagens, pelo F10.

Fig. 01 - Interface gráfica da página inicial do programa Fraps.

\footnotetext{
${ }^{6}$ Disponível em: <http://www.fraps.com/>. Acesso em: 09 ago. 2014.
} 


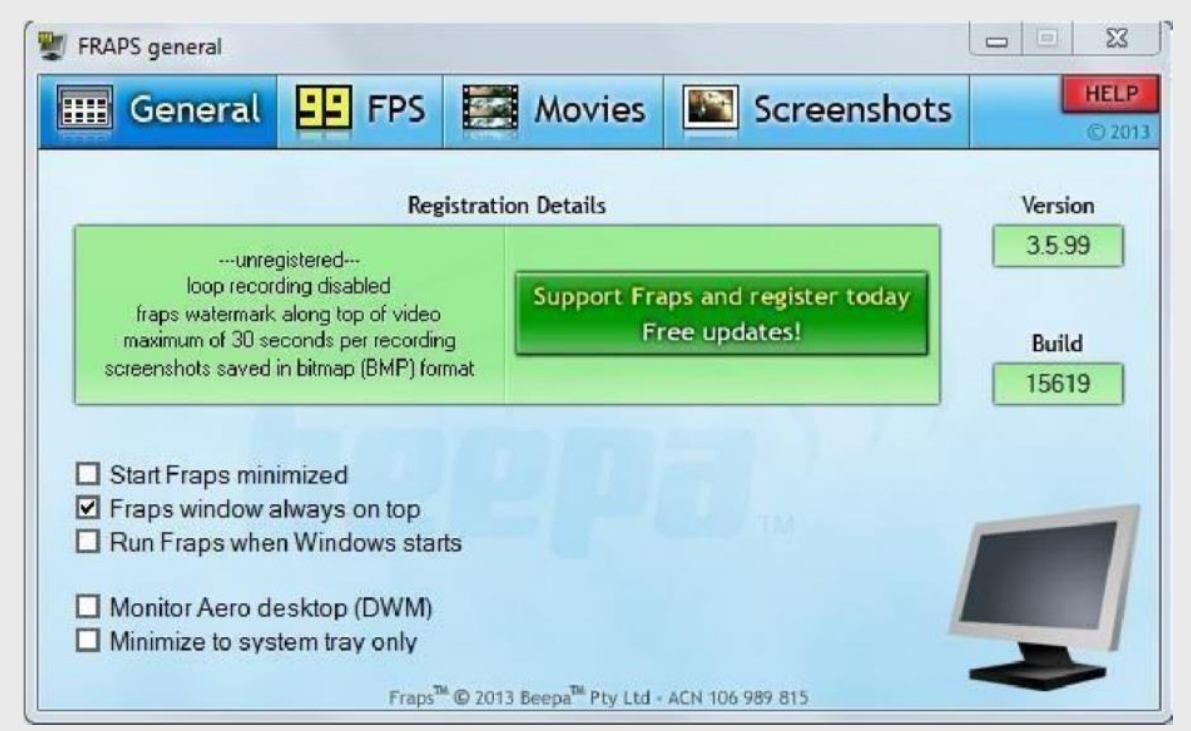

SILVA, J. M. V. Legendar ou não? Os gaps e seus sentidos no filme $O$ Buraco. Campina Grande: PIBIC/CNPq, 2014.

Para compilar as cenas constituídas por imagens em movimento seguimos estes passos: i) execução do programa Fraps; ii) inserção do filme $O$ Buraco em DVD no computador; iii) inicialização do filme por um programa de vídeo (Media Player Classic); iv) escolha de 43 cenas, tendo de 01 a 29 segundos, correspondendo a representação de aspectos intersemióticos determinados neste artigo. As cenas foram salvas automaticamente numa pasta criada pelo programa.

Em seguida, também pelo Fraps, selecionamos 43 imagens estáticas a partir das cenas acima mencionadas. As imagens apresentam momentos dos trechos do filme que evidenciam a presença de aspectos intersemióticos como aqui determinados. Tendo o filme em execução no computador, pausamos em cada momento específico das cenas mencionadas acima e pressionamos o botão F10. Cada imagem correspondente foi salva automaticamente numa pasta criada pelo programa. Das 43 cenas supracitadas, que geraram um número equivalente de imagens estáticas, 11 foram sem legendas (26\%) e 32 com legendas (74\%). O Gráfico 01 a seguir apresenta os resultados quantitativos da pesquisa.

Gráf. 01 - Quantificação de cenas sem e com legendas

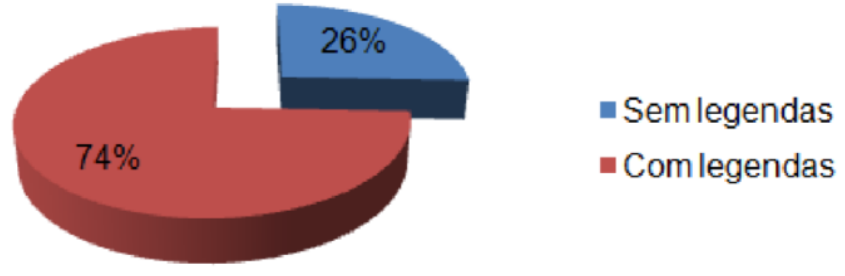


SILVA, J. M. V. Legendar ou não? Os gaps e seus sentidos no filme $O$ Buraco. Campina Grande: PIBIC/CNPq, 2014.

Há três tabelas com legendas em inglês e português, as quais foram transcritas neste artigo fielmente como exibidas na tela durante os diálogos entre os personagens.

\section{A Tradução Intersemiótica no filme $O$ Buraco}

A seguir, analisaremos 06 das 43 cenas selecionadas, três sem legendas e outras três com legendas, pois estas representam o trauma de infância de cada personagem e sua dissolução. Para a situação de cada personagem, focaremos em duas cenas: a primeira evidencia seu conflito com outrem; e, a segunda, a dissolução desse conflito. Neste momento, decidimos trabalhar com cenas legendadas e não legendadas a fim de cumprirmos os outros dois passos da pesquisa, a saber, a comparação dos aspectos linguísticos com os não linguísticos, bem como a implicação e a relevância do uso da tradução intersemiótica em contexto cinematográfico.

4.1 Lucas e o palhaço Ima. 01 - O personagem Lucas (re)encontra o seu medo, o palhaço, quando este lhe puxa para o fundo da piscina.

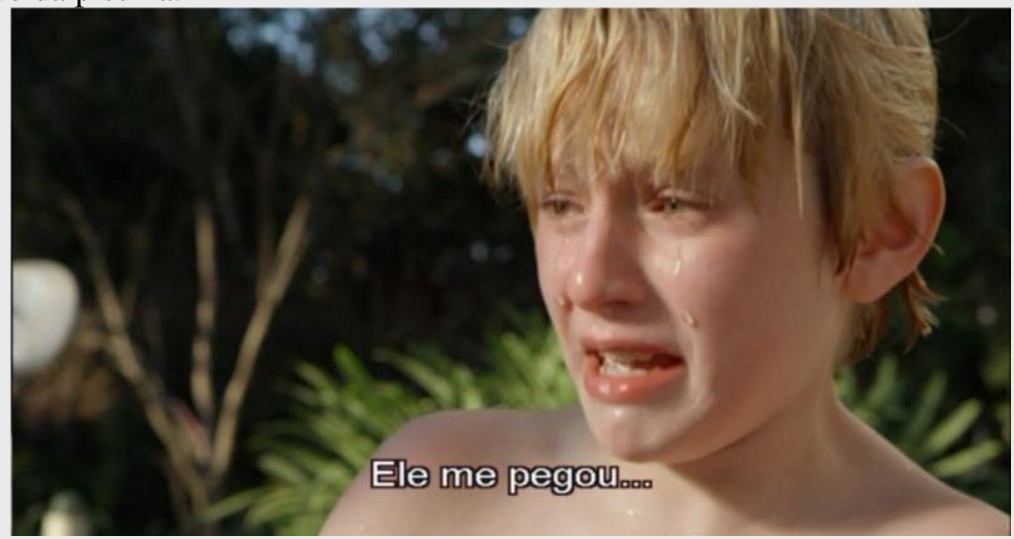

O BURACO. Direção: Joe Dante. Produção: Chris Bender; J. C. Spink; Gary Michael Walters. Los Angeles: Bold Films; BenderSpink, 2009.

Dentre várias cenas do filme, a Imagem 01 (00:55:20) enfatiza o medo que o personagem Lucas tem enfrentado ao longo de sua vida: palhaços. Antes do problema retratado no contexto acima, Lucas e um palhaço, caracterizado como bobo da corte, já estiveram cara a cara em um conflito iminente. Em outros encontros com o seu "medo", não 
houve comunicação verbal entre ambos, fazendo com que a imagem ganhasse relevância e funcionasse como suporte para compreensão (BERNARDET, 2006; SANTAELLA, 2005).

Nesta cena em estudo, Dane e Julie tiram o garoto da piscina após ter sido puxado para o fundo por alguma coisa não exibida na tela. Os três personagens são enquadrados num plano de conjunto, uma vez que são mostrados de forma reconhecível na piscina (BERNARDET, 2006).

Em seguida, Lucas, soluçando e chorando, conta que um palhaço tentara lhe afogar. Dane não acredita, argumentando que os pés do irmão possam ter ficado presos no dreno. Nesse diálogo, a câmera filma o rosto de Lucas, num primeiríssimo plano e, depois, o garoto, seu irmão e Julie, num primeiro plano (BERNARDET, 2006).

Alguns trechos do diálogo desta cena podem ser comprovados pelas legendas apresentadas na Tabela 01 .

Tab. 01 - Parte do diálogo entre os personagens na cena em que Lucas é afogado na piscina.

\begin{tabular}{|c|c|c|}
\hline & & \multirow{3}{*}{$\begin{array}{l}\text { LEGENDAS EM } \\
\text { PORTUGUES }\end{array}$} \\
\hline & $\begin{array}{l}\text { LEGENDAS EM } \\
\text { INGLÊS }\end{array}$ & \\
\hline Dane & Lucas! & \\
\hline Julie & You're okay. & Tudo bem? \\
\hline Dane & Are you all right? & Você está bem? \\
\hline \multirow{3}{*}{ Lucas } & $\begin{array}{l}\text { The clow's in there! } \\
\text { The puppet! }\end{array}$ & $\begin{array}{c}\text { O palhaço está lá, } \\
\text { o boneco... }\end{array}$ \\
\hline & $\begin{array}{l}\text { It's in the pool! } \\
\text { It grabbed me! }\end{array}$ & $\begin{array}{l}\text { Na piscina, ele me } \\
\text { pegou... }\end{array}$ \\
\hline & $\begin{array}{l}\text { It tried to pull me into } \\
\text { the hole. }\end{array}$ & $\begin{array}{l}\text {... tentou me levar } \\
\text { para o buraco. }\end{array}$ \\
\hline Dane & $\begin{array}{l}\text { Dude, it was just your } \\
\text { foot, your foot } \\
\text { probably got stuck in } \\
\text { the drain. }\end{array}$ & $\begin{array}{l}\text { Cara, eram só os } \\
\text { seus pés. } \\
\text { Deve ter prendido } \\
\text { no dreno. }\end{array}$ \\
\hline \multirow{2}{*}{ Lucas } & No, it's in there! & Não, ele estava lá. \\
\hline & It grabbed me... & Ele me pegou... \\
\hline & It pulled me. & \multirow{2}{*}{$\begin{array}{l}\text { ele me puxou, } \\
\text { não me soltava. }\end{array}$} \\
\hline & Wouldn't let go. & \\
\hline
\end{tabular}
PIBIC/CNPq, 2014. 
É importante ressaltar que, antes deste diálogo entre os personagens, houve uma construção imagética evidenciando que Lucas estava se afogando, por isso não houve possibilidades de ele exprimir verbalmente a situação, já que a imagem de medo e desespero ganhou proeminência naquele contexto. Posteriormente, como as legendas acima demonstram, houve o relato verbal do que o personagem enfrentara dentro da piscina. Desse modo, o novo signo verbal ("Ele me pegou...") surgiu desvinculando-se do original (a imagem anterior de Lucas dentro da piscina, não exibida no momento dessa conversa entre os três personagens), muito embora ainda dissesse respeito ao signo não verbal precedente, ou seja, aquela imagem deixara de ser imagem para ser complementada pelo código linguístico posterior numa nova imagem (01), representando um desespero motivado por uma ação anterior. Desse modo, se os signos precisam de outros para significar, eles “[...] têm tendência a formar novos objetos imediatos, novos sentidos e novas estruturas que, pela sua própria característica diferencial, tendem a se desvincular do original." (PLAZA, 1987, p. 30).

No que concernem as legendas da Tabela 01 e aquela exibida na Imagem 01, todas têm de uma a duas linhas, requisito necessário de acordo com Díaz Cintas e Remael (2007), e surgem em tempo específico vinculado às imagens e não ocupando tanto espaço na parte inferior da tela, condição requerida como apontada por Georgakopoulou (2009).

Em outro momento de $O$ Buraco, quando da dissolução do conflito de Lucas, ele luta com o palhaço no porão da sua casa, que é, em seguida, cortado em pedaços por um ventilador.

Ima. 02 - O palhaço é destruído pelo ventilador do porão após lutar com Lucas. 


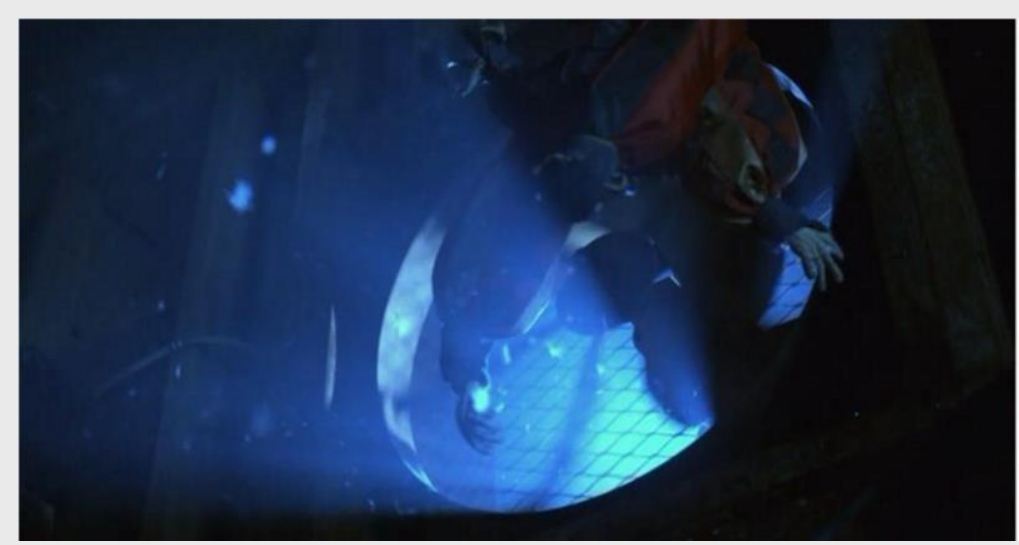

O BURACO. Direção: Joe Dante. Produção: Chris Bender; J. C. Spink; Gary Michael Walters. Los Angeles: Bold Films; BenderSpink, 2009.

A Imagem 02 (01:10:49) compõe uma sequência imagética exibindo a destruição do palhaço quando da luta com Lucas. Antes de ser destruído em pedaços, o boneco encarava o garoto que se protegia com um escudo, sendo ambos enquadrados pela câmera num plano americano (BERNARDET, 2006).

Ainda filmado nesse mesmo plano, Lucas, amedrontado, aumentou a velocidade do ventilador, abaixou-se e ficou fora do campo de visão da câmera, cujo foco passou apenas para o ventilador que girava rapidamente. Instantaneamente, o palhaço pulou do chão como se fosse atacar e se segurar no pescoço do garoto, mas foi cortado em pedaços pelas hélices. Nesse momento, ouve-se a música que se faz presente na cena, reiterando as emoções e agindo sobre os espectadores (BERNARDET, op. cit.).

Fazendo uma comparação entre a cena legendada anterior com esta, nota-se que a Imagem 01 funcionou como comprovação verbal e não verbal para compreensão da trama, através, respectivamente, da legenda "ele me pegou" e da situação imagética representando o desespero do garoto, evidenciando o apoio da informação visual no processamento da legenda (GEORGAKOPOULOU, op. cit.). Entretanto, o palhaço não foi exibido na imagem. Assim, a existência desse boneco só se deu por meio da tradução intersemiótica entre a expressão do garoto e o "ele" (considerando a cena do afogamento) (JAKOBSON, 2000; OUSTINOFF, 2011; PLAZA, 1987). Além disso, a Imagem 02 veio demonstrar o palhaço e como a situação foi resolvida, solucionando o trauma de Lucas através da troca constante de planos, da escuridão do porão, do cenário, dos sons ao fundo, dos gestos de ambos os personagens se enfrentando e da destruição do boneco em si (BERNARDET, 
2006; SANTAELLA, 2005). Desse modo, se a Imagem 01 evidencia o conflito desse personagem fazendo uso de duas linguagens trabalhando conjuntamente, a Imagem 02 comprova esse fato exibindo a dissolução do horror vivido por Lucas sem uso de legendas.

\subsection{O trauma de Julie}

Ima. 03 - O fantasma da garotinha, Annie Smith, aparece para sua amiga de infância, Julie.

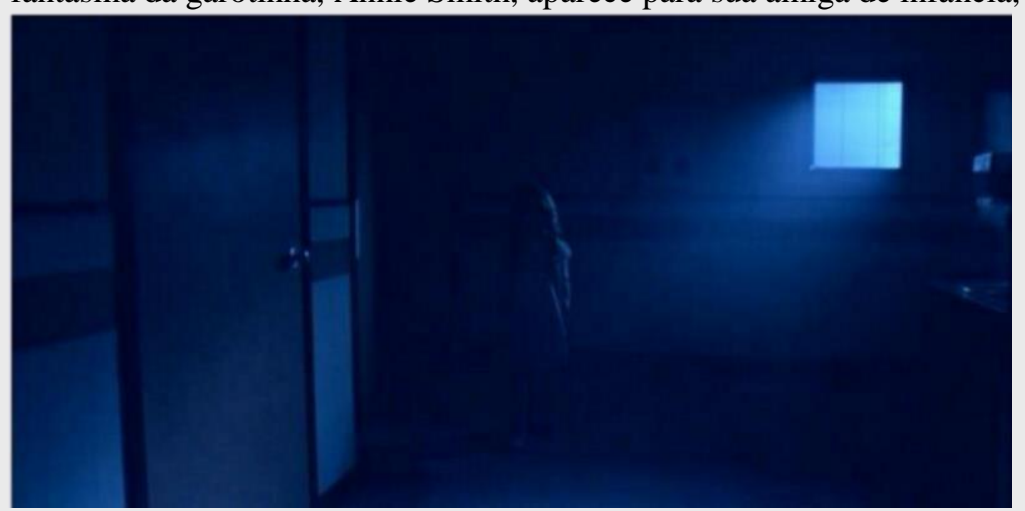

O BURACO. Direção: Joe Dante. Produção: Chris Bender; J. C. Spink; Gary Michael Walters. Los Angeles: Bold Films; BenderSpink, 2009.

A Imagem 03 (00:26:13) faz parte da cena na qual Julie vai ao banheiro de uma cafeteria. Quando a luz do aposento apaga, uma garotinha sai mancando de uma cabine e Julie vai até a porta tentando abri-la, ao mesmo tempo em que aperta o interruptor para que a luz acenda novamente.

Percebe-se a câmera filmando as pernas do espectro que sai mancando pela porta, que range lentamente. Em "plano médio", o foco é dado à personagem que caminha em direção à Julie, ressaltando "[...] uma pequena faixa de espaço acima da cabeça e embaixo dos pés [...]" (BERNARDET, op. cit., p. 38). Assim que as luzes apagam e o ambiente tornase parcialmente escuro, a atmosfera de medo se instaura no banheiro. Em seguida, nesse mesmo plano, a câmera filma Julie bastante assustada, e depois volta para a garotinha que se move devagar, sugerindo uma perseguição mórbida.

À medida que o espectro se aproxima de Julie, a câmera corta no busto da personagem, em primeiro plano (BERNARDET, op. cit.). O semblante da adolescente parece preocupante e, enfim, pergunta: “Olá?”, mas não recebe resposta. Ainda assim, como 
se Julie encarasse o fantasma, a câmera filma apenas os rostos das personagens, indo da face da garotinha de vestido branco para a da adolescente, em um primeiríssimo plano (BERNARDET, 2006). Pode-se ouvir, também, a música que reforça a “[...] exasperação na iminência do perigo [...]” (BERNARDET, op. cit., p. 47). A cena acaba quando outras meninas entram no banheiro, acendem as luzes, Julie sai e a garotinha desaparece como se nunca estivesse estado ali.

Nessa cena, observa-se a ausência de legendas devido à falta de diálogos, o que coloca em destaque a imagem, sons e gestos, evidenciando sua relevância como fontes fundamentais na construção do trauma de Julie, sugerindo, assim, que o medo que a personagem enfrenta é o espectro que lhe persegue (BERNARDET, op. cit.; SANTAELLA, 2005). Até esse momento do filme, Julie ainda não reconhece que o que lhe assombrara no banheiro é o fantasma de sua amiga de infância, Annie Smith, que caíra de um carrinho da montanha-russa do parque de diversões da cidade. Nesse acidente, ambas estavam juntas, mas Julie não conseguira segurar a amiga e a deixou cair.

Julie tem vivido com uma culpa que atravessa anos, e só após a abertura do buraco, a atmosfera ao redor tem mudado. Essa cena exibe a adolescente se esgueirando, buscando se encostar à parede como refúgio. Além disso, a situação imagética representa a pouca iluminação no banheiro, cuja única luz é aquela que entra no aposento pela janela, parecendo dar ênfase ao predador que encurrala a presa (BERNARDET, op. cit.).

Procedendo a trama, Julie para de fugir da culpa que lhe persegue e decide voltar ao parque de diversões onde tudo começara para resolver a sua situação com Annie. Ima. 04 O fantasma da garotinha e Julie discutem na montanha-russa, local onde Annie Smith morrera muitos anos atrás.

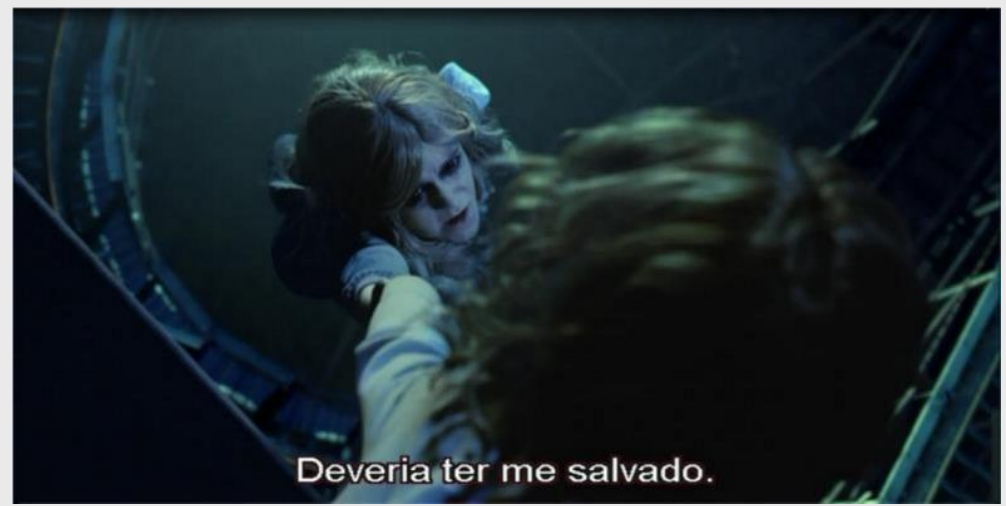


O BURACO. Direção: Joe Dante. Produção: Chris Bender; J. C. Spink; Gary Michael Walters. Los Angeles: Bold Films; BenderSpink, 2009.

A Imagem 04 (01:06:43) congela o momento no qual o fantasma de Annie está pendurado pela mão de Julie. Num plano americano, a câmera corta no busto da adolescente (BERNARDET, 2006). Em seguida, filma, de cima, sobre a cabeça de Julie, sugerindo, ao menos nesse caso, que quem fala não é aquela cujo rosto não é filmado, mas sim a garotinha que olha para cima, pálida e sem vida.

Na Tabela 02, encontram-se partes do diálogo desta cena. 
Tab. 02 - Parte do diálogo entre os personagens na cena em que Julie (re)encontra seu medo.

\begin{tabular}{|c|c|c|}
\hline & $\begin{array}{l}\text { LEGENDAS EM } \\
\text { INGLÊS }\end{array}$ & $\begin{array}{l}\text { LEGENDAS EM } \\
\text { PORTUGUÊS }\end{array}$ \\
\hline \multirow{3}{*}{ Annie } & It's okay. & Tudo bem. \\
\hline & $\begin{array}{l}\text { We're so high. Just like } \\
\text { before. }\end{array}$ & $\begin{array}{l}\text { Estamos tão alto, } \\
\text { como antes. }\end{array}$ \\
\hline & You let me fall! & $\begin{array}{l}\text { Você me deixou } \\
\text { cair! }\end{array}$ \\
\hline \multirow{3}{*}{ Julie } & No! & Não! \\
\hline & Hang on! & Segure! \\
\hline & Annie, hold on. & $\begin{array}{l}\text { Annie, segure } \\
\text { firme! }\end{array}$ \\
\hline Annie & $\begin{array}{l}\text { You should have saved } \\
\text { me! }\end{array}$ & $\begin{array}{l}\text { Deveria ter me } \\
\text { salvado. }\end{array}$ \\
\hline Julie & I know. I wanted to! & Eu sei, eu queria. \\
\hline \multirow{2}{*}{ Annie } & $\begin{array}{l}\text { But you didn't. } \\
\text { You just sat there } \\
\text { crying. }\end{array}$ & $\begin{array}{l}\text { Mas não salvou, } \\
\text { ficou chorando. }\end{array}$ \\
\hline & $\begin{array}{l}\text { Even when the } \\
\text { policeman heard us. } \\
\text { When he fell. }\end{array}$ & $\begin{array}{l}\text { Até quando o } \\
\text { policial ouviu. } \\
\text { Quando ele caiu. }\end{array}$ \\
\hline Julie & I tried. I couldn't. & $\begin{array}{l}\text { Eu tentei, não } \\
\text { pude. }\end{array}$ \\
\hline Annie & You let me die. & $\begin{array}{l}\text { Você me deixou } \\
\text { morrer. }\end{array}$ \\
\hline Julie & $\begin{array}{l}\text { I was scared! I was so } \\
\text { scared! }\end{array}$ & $\begin{array}{l}\text { Eu tive medo. } \\
\text { Muito medo. }\end{array}$ \\
\hline Julie $^{\substack{\text { Annie } \\
\&}}$ & $\begin{array}{l}\text { - You aren't scared } \\
\text { anymore? } \\
\text { - No. Not anymore. }\end{array}$ & $\begin{array}{l}\text { - Não tem mais } \\
\text { medo? } \\
\text { - Não, não tenho. }\end{array}$ \\
\hline \multirow{2}{*}{ Annie } & That's good. & Que bom. \\
\hline & Bye, Julie. & Adeus, Julie. \\
\hline
\end{tabular}

SILVA, J. M. V. Legendar ou não? Os gaps e seus sentidos no filme $O$ Buraco. Campina Grande: PIBIC/CNPq, 2014.

A Imagem 04 faz parte de uma construção imagética que recriou o incidente passado de Annie (BERNARDET, op. cit.). Por meio da tradução intersemiótica, o diálogo entre as personagens confirmou essa sequência imagética, bem como deu suporte para a situação ainda não resolvida entre ambas, trazendo à tona, assim, as perguntas ainda não respondidas e as respostas esperadas (JAKOBSON, 2000; OUSTINOFF, 2011; PLAZA, 1987).

Observa-se que as legendas transcritas e apresentadas na Tabela 02 e aquela presente na Imagem 04 comprovam os requisitos elencados por Díaz Cintas e Remael 
(2007) e Georgakopoulou (2009), no que diz respeito ao tamanho de uma ou duas linhas, e ao tempo de duração e ao pequeno espaço ocupado na tela, respectivamente.

Relacionando a Imagem 03 não legendada com a Imagem 04, percebe-se que a Imagem 03 demonstrou a perseguição mórbida de Annie a Julie através da mudança de planos, os sons (o sapato do fantasma batendo no chão e ecoando no banheiro), o cenário, a escuridão do ambiente e os gestos das personagens se encarando (BERNARDET, 2006; SANTAELLA, 2005). A Imagem 04, tendo o suporte do código linguístico, proveu mais informações sobre o porquê de Annie e Julie estarem naquele conflito a ser resolvido. Assim, embora a Imagem 03 não tenha linguagem verbal, a narrativa pode se compreendida pelo espectador, e a Imagem 04 possibilitou uma maior compreensão ao apresentar as linguagens verbal e não verbal trabalhando significativamente (JAKOBSON, 2000; OUSTINOFF, 2011; PLAZA, 1987).

\subsection{O conflito de Dane}

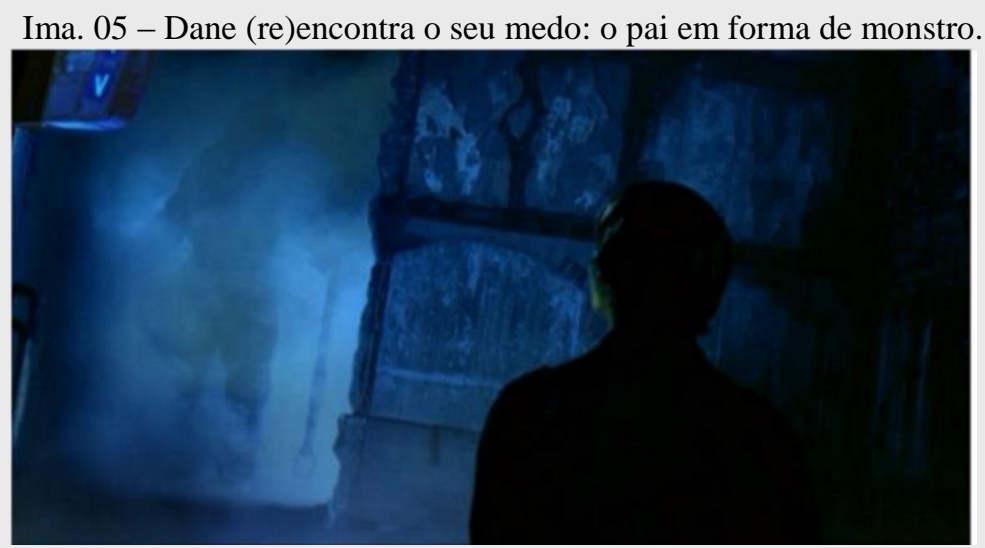

O BURACO. Direção: Joe Dante. Produção: Chris Bender; J. C. Spink; Gary Michael Walters. Los Angeles: Bold Films; BenderSpink, 2009.

A Imagem 05 (01:15:58) retrata a cena na qual Dane, após cair no buraco, chega a uma rua. Deitado no chão e em meio à penumbra, o adolescente observa os prédios tortuosos que formam a paisagem tenebrosa ao redor. Ouve Lucas gritando "Dane!" de dentro de um apartamento à frente e, sem compreender direito o que irmão mais novo lhe avisara, ele 
volta-se e observa o gigante que aparece grunhindo, cujo corpo é protegido por uma espessa camada de fumaça.

Como visto na Imagem 05, a câmera filma Dane de costas e o monstro que se levanta à frente, um pouco acima do adolescente. Nota-se a construção do cenário tenebroso que situa o gigante como um verdadeiro monstro, ante a estatura menor e mais frágil do outro personagem (BERNARDET, op. cit.). Ademais, ouve-se a música que enfatiza as emoções, envolvendo os espectadores (BERNARDET, op. cit.).

Em posse do cinto no pulso esquerdo, o monstro segue em direção a Dane, que se afasta tropeçando para trás em busca de refúgio. Através do primeiríssimo plano (BERNARDET, op. cit.), a câmera enquadra o rosto estonteante de um homem de longos cabelos e olhos brancos que se impõe sobre Dane. Num plano americano, o adolescente é filmado recostado num portão de um armazém (BERNARDET, 2006).

A câmera, filmando o adolescente de cima como se fosse os olhos do monstro, desce e focaliza Dane cortando-o no busto, num primeiro plano (BERNARDET, op. cit.). $\mathrm{O}$ garoto se abaixa e rola para a direita, de modo a proteger-se de um soco que o gigante lançara sobre ele e, por sorte, atingira a parede cujos tijolos quebraram e se soltaram ao chão. Enquadrado num plano médio (BERNARDET, op. cit.), Dane olha ao redor, com medo e à procura de mais ameaça, mas sobe por uma escada para o andar do apartamento, onde entra pela janela.

Percebe-se que não há legendas retratando o (re)encontro pai-filho pela ausência de diálogos. Assim, o conflito entre ambos os personagens é enfatizado principalmente pela construção imagética, cenários e sons (BERNARDET, op. cit.; SANTAELLA, 2005).

Ima. 06 - O monstro (o pai) em desconstrução luta com Dane. 


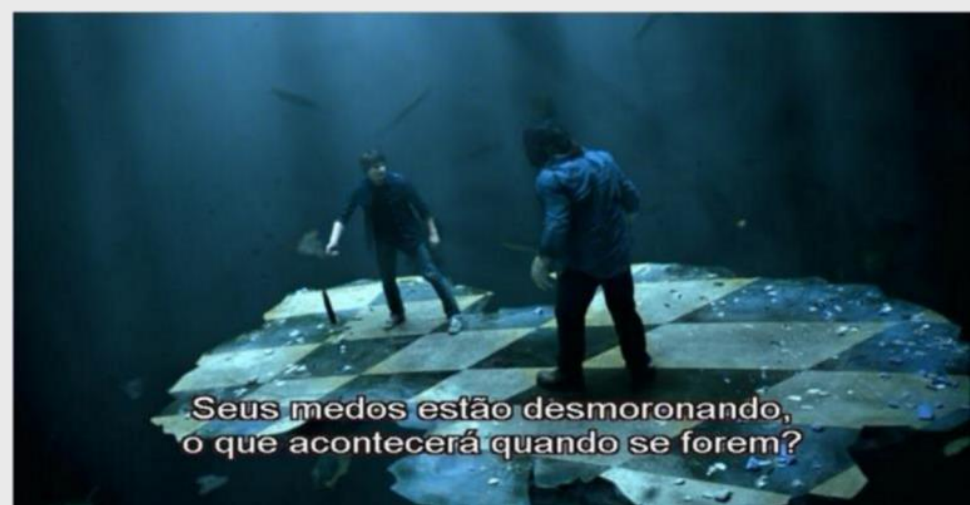

O BURACO. Direção: Joe Dante. Produção: Chris Bender; J. C. Spink; Gary Michael Walters. Los Angeles: Bold Films; BenderSpink, 2009.

A Imagem 06 (01:23:30) exibe uma parte da cena em que a câmera enquadra os personagens num plano de conjunto (BERNARDET, op. cit.) e representa o monstro em confronto com Dane. Além de ser construído primordialmente nesse plano, o trecho da cena mostra, em outro momento, o adolescente e o gigante sendo cortados na cintura, num plano americano (BERNARDET, op. cit.).

Não sendo reconhecida pelo adolescente como sendo, de fato, seu pai, a figura do monstro começa a definhar. Tornando-se mais frágil e sem forças do que antes, sua estatura diminui, seu rosto está mais à vista, ainda protegido pelos longos cabelos, e suas mãos parecem lentamente voltar à aparência humana. Como visto na Imagem 06, Dane luta sobre o chão flutuante. Agora, mais forte do que seu pai, o adolescente está em poder do cinto que fora usado para lhe bater quando criança.

Ao final da cena, o adolescente gira o cinto em menção a bater no pai, mas prendeo no ventilador acima quando o pai pula sobre si. O pai fica pendurado numa ponta do piso flutuante em meio ao cenário giratório e em desconstrução, tentando subir, agora em total forma de homem e com o rosto inteiramente à mostra, sendo exibido num primeiro plano (BERNARDET, 2006). Dane lança o cinto para baixo, quebrando a parte do chão na qual os braços do pai se prendiam, levando o vilão a cair para dentro da escuridão do buraco.

Na Tabela 03, são apresentados alguns trechos da cena do conflito entre Dane e seu pai. 
Tab. 03 - Parte do diálogo na cena sobre o confronto entre Dane e o monstro (o pai).

\begin{tabular}{|c|c|c|}
\hline & LEGENDAS EM & LEGENDAS EM \\
\hline & INGLES & PORTUGUES \\
\hline \multirow[t]{2}{*}{ Dane } & I'm not scared of you. & $\begin{array}{l}\text { Não tenho medo } \\
\text { de você. }\end{array}$ \\
\hline & I'm not scared! & Não tenho medo! \\
\hline \multirow[t]{2}{*}{ Pai } & $\begin{array}{c}\text { We wouldn't be here } \\
\text { if that was true. }\end{array}$ & $\begin{array}{l}\text { Não estaria aqui, se } \\
\text { fosse verdade. }\end{array}$ \\
\hline & $\begin{array}{l}\text { You have been afraid } \\
\text { your whole life. }\end{array}$ & $\begin{array}{l}\text { Vai ter medo a } \\
\text { vida toda. }\end{array}$ \\
\hline \multirow{2}{*}{ Dane } & Not anymore. & Não mais. \\
\hline & $\begin{array}{l}\text { Because you can't hurt } \\
\text { me now. }\end{array}$ & $\begin{array}{l}\text { Porque não pode } \\
\text { me ferir. }\end{array}$ \\
\hline Pai & $\begin{array}{l}\text { Tell me, boy. Did that } \\
\text { hurt? }\end{array}$ & $\begin{array}{l}\text { Diga, menino, isso } \\
\text { doeu? }\end{array}$ \\
\hline \multirow{4}{*}{ Dane } & $\begin{array}{l}\text { I know you're not this } \\
\text { big. }\end{array}$ & $\begin{array}{l}\text { Sei que você não é } \\
\text { tão grande. }\end{array}$ \\
\hline & $\begin{array}{l}\text { You just look like } \\
\text { cause I was little. }\end{array}$ & $\begin{array}{l}\text { Você só parecia } \\
\text { ser, } \\
\text { porque eu era } \\
\text { pequeno. }\end{array}$ \\
\hline & $\begin{array}{l}\text { That's why you came } \\
\text { after us. } \\
\text { Because you were } \\
\text { mean. }\end{array}$ & $\begin{array}{c}\text { Por isso nos batia, } \\
\text { porque era mau. }\end{array}$ \\
\hline & $\begin{array}{l}\text { But you were just } \\
\text { scared. You were } \\
\text { scared of everybody } \\
\text { else. Weren't you? }\end{array}$ & $\begin{array}{l}\text { Mas você tinha } \\
\text { medo. } \\
\text { Tinha medo de } \\
\text { todo mundo, não? }\end{array}$ \\
\hline Pai & $\begin{array}{l}\text { Do I look scared to } \\
\text { you? }\end{array}$ & $\begin{array}{l}\text { Parece que estou } \\
\text { com medo? }\end{array}$ \\
\hline Dane & Do I? & E eu? \\
\hline Pai & $\begin{array}{l}\text { Your fears are falling } \\
\text { away, boy. } \\
\text { What happens to you } \\
\text { when they're gone? }\end{array}$ & $\begin{array}{l}\text { Seus medos estão } \\
\text { desmoronando, o } \\
\text { que acontecerá } \\
\text { quando se forem? }\end{array}$ \\
\hline
\end{tabular}

SILVA, J. M. V. Legendar ou não? Os gaps e seus sentidos no filme $O$ Buraco. Campina Grande: PIBIC/CNPq, 2014. 
As legendas acima evidenciam tanto o confronto entre o pai e Dane em dissolução, quanto a história que eles tiveram juntos (JAKOBSON, 2000; OUSTINOFF, 2011; PLAZA, 1987). É perceptível que o pai repetitivamente faz menção ao medo que ele sempre impôs sobre Dane, até inesperadamente perceber que o filho não mais sente medo dele.

Diante das palavras verdadeiras do adolescente, o medo de Dane começa a diluir, tomando os primeiros passos para que seu conflito com o pai possa se resolver de uma vez por todas. Assim, o cenário, que já vinha sendo destruído anteriormente pela violência física do próprio pai, desmorona-se ainda mais e o monstro é enfim derrotado.

Outro ponto a se destacar volta-se para as legendas da Tabela 03 e da Imagem 06. Percebe-se que algumas têm duas linhas e outras uma (DÍAZ CINTAS; REMAEL, 2007), e o tempo de duração e o espaço limitado ocupado na tela são características recorrentes (GEORGAKOPOULOU, 2009).

Analisando as Imagens 05 e 06, nota-se que, a Imagem 05 confirmou apenas imageticamente o conflito de Dane, exibindo várias mudanças de planos, os sons (ruído produzido pelo monstro), o cenário, a névoa e a escuridão da rua, e a perseguição do monstro ao adolescente (BERNARDET, 2006; SANTAELLA, 2005). Por meio da tradução intersemiótica, a Imagem 06 apresentou mais um veículo que auxiliou na compreensão da cena, as legendas, que confirmam, pela pergunta do pai, o motivo do cenário e ele mesmo em desmoronamento (JAKOBSON, 2000; OUSTINOFF, 2011; PLAZA, 1987). Assim, apesar de a Imagem 05 não ter linguagem verbal, ainda pode-se compreender a narrativa, e a Imagem 06 forneceu mais conteúdo para compreensão, apresentando, significativamente, os códigos verbal e não verbal em conjunto.

\section{Considerações finais}

Com este artigo, descrevemos o uso da tradução intersemiótica no filme $O$ Buraco, através da compilação, quantificação e estudo de cenas, com o intuito de analisar as implicações de tal técnica tradutória e seu resultado em contexto fílmico. 
Baseando-nos nos pressupostos teóricos de Jakobson (op. cit.), Oustinoff (op. cit.) e Plaza (op. cit.), pudemos conferir a tradução entre signos verbais e não verbais, pois comprovamos sua relevância para a compreensão da trama em estudo e enfatizamos que,

"para dar sentido ao mundo, a relação do homem com o universo ao redor é permeada pelos signos." (PLAZA, op. cit., p. 19).

Tendo em vista os dados quantitativos coletados, 11 cenas sem legendas (26\%) e 32 com legendas (74\%), foi notável que, mesmo que o número de cenas sem código linguístico tenha sido menor do que as demais, ainda representa um montante considerável que trabalha significativamente para a compreensão da narrativa em $O$ Buraco. Além disso, as cenas com código linguístico também auxiliam aquelas sem legendas, pois, além de ter código verbal, a imagem é fundamental para o trato de conflitos particulares dos personagens e da superação do medo de cada um deles.

Com relação aos dados qualitativos, notou-se que a predominância da linguagem não-verbal nas cenas sem legendas estudadas ocorreu por não apresentar diálogos nem monólogos, pois a imagem trabalhou para retratar o medo, o desespero e a dissolução do conflito dos personagens, em consonância com a mudança constante de planos, sons, cenários e gestos dos personagens (BERNARDET, 2006; SANTAELLA, 2005), que, conjuntamente, contribuíram para a tradução não verbal da ideia da trama sem perdas de sentido (JAKOBSON, 2000; OUSTINOFF, 2011; PLAZA, 1987).

Assim sendo, no presente contexto, dissociar totalmente a imagem da legenda, hegemonizando a primeira sobre a segunda, não foi possível, pois, como visto, elas precisam estar juntas de modo que a compreensão da trama possa ser atingida eficientemente.

\section{Agradecimentos}

Este artigo foi realizado com apoio do $\mathrm{CNPq}$, Conselho Nacional de Desenvolvimento Científico e Tecnológico - Brasil, fruto da pesquisa PIBIC/CNPq/UFCG, (ciclo 2013-2014), Legendar ou não? Os gaps e seus sentidos no filme O Buraco. Além disso, agradecemos à professora Dra. Sinara de Oliveira Branco a orientação dos trabalhos. 


\section{Referências}

BERNARDET, Jean-Claude. O que é cinema. São Paulo: Brasiliense, 2006.

CINEMATÓGRAFO. In: PRIBERAM. Lisboa: Priberam Informática, 2015. Disponível em: <http://www.priberam.pt/dlpo/cinematografo>. Acesso em: 27 jan. 2015.

DÍAZ CINTAS, Jorge; REMAEL, Aline. Audiovisual translation: subtitling. Manchester: St. Jerome, 2007.

GEORGAKOPOULOU, Panayota. Subtitling for the DVD industry. In: DÍAZ CINTAS, Jorge; ANDERMAN, Gunilla. Audiovisual translation: language transfer on screen.

Great Britain: Palgrave Macmillan, 2009, p. 21-36.

JAKOBSON, Roman. On linguistic aspects of translation. In: VENUTI, Lawrence. (Ed.). The translation studies reader. London / New York: Routledge, 2000, p. 113118.

LUYKEN, Georg-Michael et al. (Ed.). Overcoming language barriers in television: dubbing and subtitling for the European audience. Manchester: European Institute for the Media, 1991.

MOREIRA, Herivelto; CALEFFE, Luiz Gonzaga. Metodologia de pesquisa para o professor pesquisador. 2. ed. Rio de Janeiro: Lamparina, 2008.

O BURACO. Direção: Joe Dante. Produção: Chris Bender; J. C. Spink; Gary Michael Walters. Intérpretes: Chris Massoglia; Haley Bennett; Nathan Gamble; Teri Polo; Bruce Dern; Quinn Lord; John DeSantis; Douglas Chapman; Mark Pawson. Roteiro: Mark L. Smith. Los Angeles: Bold Films; BenderSpink, 2009. 1 DVD (92 min), widescreen, color. OUSTINOFF, Michael. Tradução: história, teorias e métodos. Trad. Marcos Marcionilo. São Paulo: Parábola Editorial, 2011.

PLAZA, Julio. Tradução intersemiótica. São Paulo: Perspectiva, 1987.

SANTAELLA, Lucia. O que é semiótica. São Paulo: Brasiliense, 2005.

SANTORO, André. O cinematógrafo dos Lumière. Guia do Estudante, São Paulo, fev. 2007, Seção Aventuras na História. Disponível em:

<http://guiadoestudante.abril.com.br/aventurashistoria/cinematografolumiere435113.shtml> . Acesso em: 27 jan. 2015.

SOKOLI, Stavroula. Subtitling norms in Greece and Spain. In: CINTAS, Jorge Díaz; ANDERMAN, Gunilla. Audiovisual translation: language transfer on screen. Great Britain: Palgrave Macmillan, 2009, p. 36-48. 